\title{
PENGARUH MODEL PEMBELAJARAN KOOPERATIF TIPE TIME TOKEN TERHADAP HASIL BELAJAR IPA TEMA 8 DI SEKOLAH
}

\author{
${ }^{1}$ Medlin Lumban Gaol, Ratnawati ${ }^{2}$, Fitri Handayani ${ }^{3}$ \\ ${ }^{1}$ Mahasiswa Universitas Dharmas Indonesia \\ ${ }^{2,3}$ DosenUniversitasDharmas Indonesia \\ Email:medlinlumbangaol17@gmail.com
}

\begin{abstract}
ABSTRAK
Penelitian ini dilatarbelakangi oleh hasil belajar siswa pada pembelajaran IPA tema 8 di sekolah dasar. Penelitian ini bertujuan untuk mengetahui ada tidaknya pengaruh model pembelajaran kooperatif tipe Time Token terhadap hasil belajar IPA tema 8 di sekolah dasar. Jenis penelitian ini adalah penelitian pra eksperimen dengan desain One Group Pretest-Postest Design. Populasi penelitian ini adalah seluruh siswa kelas V SDN 06 Sitiung Dharmasraya. Teknik pengambilan sampel yang digunakan dalam penelitian ini adalah sampling jenuh. Dan sampel penelitian ini adalah kelas V yang berjumlah 23 siswa. Teknik pengumpulan data yang digunakan dalam penelitian ini adalah tes tertulis. Teknik analisis data yang digunakan dalam penelitian ini adalah uji normalitas dan uji hipotesis melalui SPSS 20 pada taraf 0,05. Hasil penelitian menunjukkan bahwa model pengaruh Time Token memberikan pengaruh yang baik terhadap hasil belajar IPA siswa, hal ini terlihat dari perolehan rata-rata nilai pre-test dan post-test yang diperoleh dari siswa kelas $\mathrm{V}$ dengan perolehan rata-rata The rata-rata pre-test adalah 66 dan post-test adalah 77. Berdasarkan analisis yang dilakukan, diperoleh nilai signifikansi model pembelajaran Time Token.
\end{abstract}

Kata kunci: Model Time Token, Hasil Belajar IPA di Sekolah Dasar.

\begin{abstract}
This research is motivated by student learning outcomes in science learning theme 8 in elementary schools. This study aims to determine whether there is an effect of the Time Token type of cooperative learning model on the learning outcomes of science theme 8 in elementary schools. This type of research is a pre-experimental research with One Group Pretest-Postest Design. The population of this study were all fifth grade students of SDN 06 Sitiung Dharmasraya. The sampling technique used in this research is saturated sampling. And the sample of this research is class V, totaling 23 students. The data collection technique used in this study was a written test. The data analysis technique used in this research is normality test and hypothesis testing through SPSS 20 at 0.05 level. The results showed that the Time Token influence model gave a good influence on students' science learning outcomes, this can be seen from the average pre-test and post-test scores obtained from fifth grade students with the average
\end{abstract}


pre-test scores. -test is 66 and post-test is 77 . Based on the analysis, the significance value of the Time Token learning model is obtained.

Keywords: Time Token Model, Science Learning Outcomes in Elementary Schools

\section{PENDAHULUAN}

Pendidikan merupakan salah satu yang menitikberatkan pada satu bidang dari semua kegiatan belajar, karena dari suatu proses belajar mengajar, pendidikan mampu mendewasakan seseorang melalui pengajaran yang mendidiknya untuk bertanggung jawab dan memiliki sikap yang baik dalam kehidupan masyarakat. Jadi, pendidikan merupakan proses untuk membangun masa depan, sehingga akan mengalami perubahan dan menyebabkan dirinya berfungsi lebih baik dalam kehidupan masyarakat (Dewi, 2017).

Pendidikan dalam pembelajaran di sekolah, pembelajaran pada hakekatnya adalah suatu proses mengatur, mengorganisasikan lingkungan disekitarnya sehingga dapat menumbuhkan dan mendorong siswa dalam proses belajar. Pada jenjang pendidikan, yaitu pendidikan sekolah dasar yang merupakan jenjang terendah dari sistem pendidikan nasional, yang telah diatur dalam Undang-Undang Nomor 20 Tahun 2003 tentang sistem pendidikan nasional. Pendidikan sekolah dasar merupakan pendidikan umum yang telah diselenggarakan selama enam tahun di sekolah dasar (Sumantri, 2003). Jadi, pendidikan sekolah dasar merupakan faktor yang sangat penting, karena pada jenjang sekolah dasar inilah landasan bagi berkembangnya kemampuan berpikir dan belajar siswa untuk mempengaruhi dan mempengaruhi pada jenjang selanjutnya.

Pendidikan saat ini sudah sesuai dengan kurikulum yang telah ditetapkan yaitu kurikulum 2013, perubahan kurikulum 2013 pada kurikulum KTSP membutuhkan kurikulum baru dimana kurikulum 2013 mengajarkan guru untuk dapat melaksanakan pembelajaran aktif khususnya di sekolah dasar, pembelajaran dilakukan akan membuat siswa termotivasi dalam pendidikan secara efektif. tematik (Indriani, 2015). Pembelajaran Tematik berfungsi untuk memberikan kemudahan bagi siswa dalam memahami dan mendalami konsep materi yang telah digabungkan menjadi satu tema (Resnani, 2014). Pembelajaran tematik menuntut siswa untuk aktif mencari, menggali, menemukan konsep dan prinsip secara holistik dan otentik. Science berasal dari bahasa Inggris natural science, secara singkat sering disebut science. Alam berarti alam yang berhubungan dengan alam berkenaan dengan lingkungan alam. Ilmu berarti tentang pengetahuan. Jadi Ilmu Pengetahuan Alam bisa disebut Ilmu Alam ini, yaitu ilmu yang 
mempelajari peristiwa-peristiwa yang terjadi di alam (Prananda, 2019). Pembelajaran IPA di sekolah dasar adalah sesuatu yang berkaitan dengan mencari tahu tentang alam secara sistematis.

Konsep IPA di sekolah dasar merupakan konsep yang masih terintegrasi karena belum dipisahkan secara terpisah, seperti kimia, biologi, fisika, IPA yang dapat diartikan sebagai upaya manusia untuk memahami alam semesta. Dengan melalui observasi, serta menggunakan prosedur dan dijelaskan dengan penalaran sehingga mendapatkan sesuatu yang disimpulkan (Prananda \& Hadiyanto 2019). Jadi sains dapat diartikan sebagai usaha manusia yang dapat memahami alam semesta melalui pengamatan langsung dengan lingkungannya dan menggunakan prosedur-prosedur yang dijelaskan dengan nalar sehingga menemukan suatu kesimpulan. Oleh karena itu, pembelajaran IPA dapat berjalan dengan hasil belajar yang diperoleh siswa. Setelah dilakukan proses pembelajaran yaitu dengan adanya hasil belajar, maka hasil belajar adalah pencapaian nilai-nilai yang telah dicapai oleh siswa, dengan tujuan pendidikan mengikuti proses belajar mengajar. Argumen ini didukung oleh (Ariyanto, 2016). Artinya belajar adalah suatu proses yang dapat membangun pengetahuan melalui transformasi pengalaman, sedangkan belajar adalah usaha sistematis untuk menata lingkungan belajar dalam rangka menumbuhkan dan mengembangkan belajar bagi siswa. Seseorang yang dikatakan sukses dapat dilihat dari puncaknya dan keberhasilan dapat dilihat dari hasil deep learning yang meliputi aspek kognitif, afektif, dan psikomotorik (Prananda, 2020).

Berdasarkan hasil observasi yang telah dilakukan di SD 06 Sitiung kelas v terdapat permasalahan yaitu kurangnya keaktifan siswa dalam pembelajaran dan diperlukan model pembelajaran yang inovatif dan menyenangkan dimana IPA menjadi salah satu nilai rendah pada siswa., hal ini banyak siswa yang diam saat berdiskusi dibandingkan aktif dalam mengemukakan pendapat dan bertanya karena siswa kebanyakan masih terlalu fokus mencatat dan kurang menguasai materi yang disampaikan guru dan siswa kurang mampu berinteraksi dengan sesama siswa yang terkesan pasif dan suasana belajar yang terkesan kaku dan membosankan yang dapat menyebabkan hasil belajar mengalami ketidaklengkapan dalam pembelajaran IPA. Artinya dari hasil observasi dapat disimpulkan disini penulis mencoba menggunakan model pembelajaran kooperatif tipe Time Token sebagai solusi untuk mengatasi permasalahan di kelas v, penulis memilih salah satu model aktif inovatif yaitu Time Token model untuk mencoba 
agar siswa dapat menjadi aktif dan lebih berani berbicara dalam mengungkapkan pendapatnya tanpa rasa takut dan malu.

Model Time Token pertama kali diperkenalkan oleh Arends pada tahun 1998 yang menyatakan bahwa model merupakan salah satu keterampilan yang berpartisipasi dalam pembelajaran kooperatif yang bertujuan untuk mengatasi pemerataan kesempatan yang menjadi ciri kerja kelompok, yaitu menghindari keheningan sama sekali dengan diberikan kupon berbicara sehingga siswa harus berbicara dan ingin bekerja. saling membantu antar kelompok anggota (Nurwati, 2017). Jadi Time Token adalah model pembelajaran kooperatif dengan mengacu pada kelompok belajar siswa dan dapat mengajak anggota kelompok kecil untuk berani dan tidak takut untuk mengungkapkan pendapatnya dan memiliki keterampilan sosial dan berinteraksi antar sesama anggota untuk aktif, dan belajar dengan menggunakan kupon yang diberikan . oleh guru. Keuntungan dari model Time Token adalah mendorong anggota siswa untuk meningkatkan inisiatif dan mencegah keheningan sama sekali dan siswa aktif dalam kegiatan pembelajaran serta meningkatkan kemampuan komunikasi yang baik antara siswa lain dengan tujuan agar setiap anggota kelompok diskusi memiliki kesempatan. untuk mendapatkan kontribusi dan mendengarkan pandangan dan pemikiran anggota lain.

\section{HASIL DAN PEMBAHASAN}

Pelaksanaan perlakuan pada kelas V di sekolah dasar 06 sitiung, penelitian ini yaitu dengan menggunakan model Time Token pada mata pelajaran IPA tema 8 Lingkungan Sahabat Kita Subtema 2 Perubahan Lingkungan . Rentang data yang dihitung dengan rumus nalai maksimal-nilai minimal, sehingga diperoleh rentang data Pre-Test yaitu:

Tabel 1 Tabel Frekuensi Pre-Test

\begin{tabular}{|l|l|l|l|l|}
\hline No & Kelas Interval & $\begin{array}{c}\text { Frekuensi } \\
\text { absolut }\end{array}$ & $\begin{array}{c}\text { Frekuensi } \\
\text { relatif }\end{array}$ & Kategori nilai \\
\hline 1 & $30-44$ & 3 & $13,0 \%$ & Sangat rendah \\
\hline 2 & $45-60$ & 4 & $17,4 \%$ & Rendah \\
\hline 3 & $61-74$ & 7 & $30,4 \%$ & Sedang \\
\hline 4 & $75-82$ & 6 & $26,1 \%$ & Tinggi \\
\hline 5 & $83-100$ & 3 & $13,0 \%$ & Sangat tinggi \\
\hline
\end{tabular}




\begin{tabular}{|l|ll|l|}
\hline & Jumlah & 23 & $100 \%$ \\
\hline
\end{tabular}

Berdasarkan distribusi variable hasil belajara dapat dilihat dari diagram batang dibawah ini:

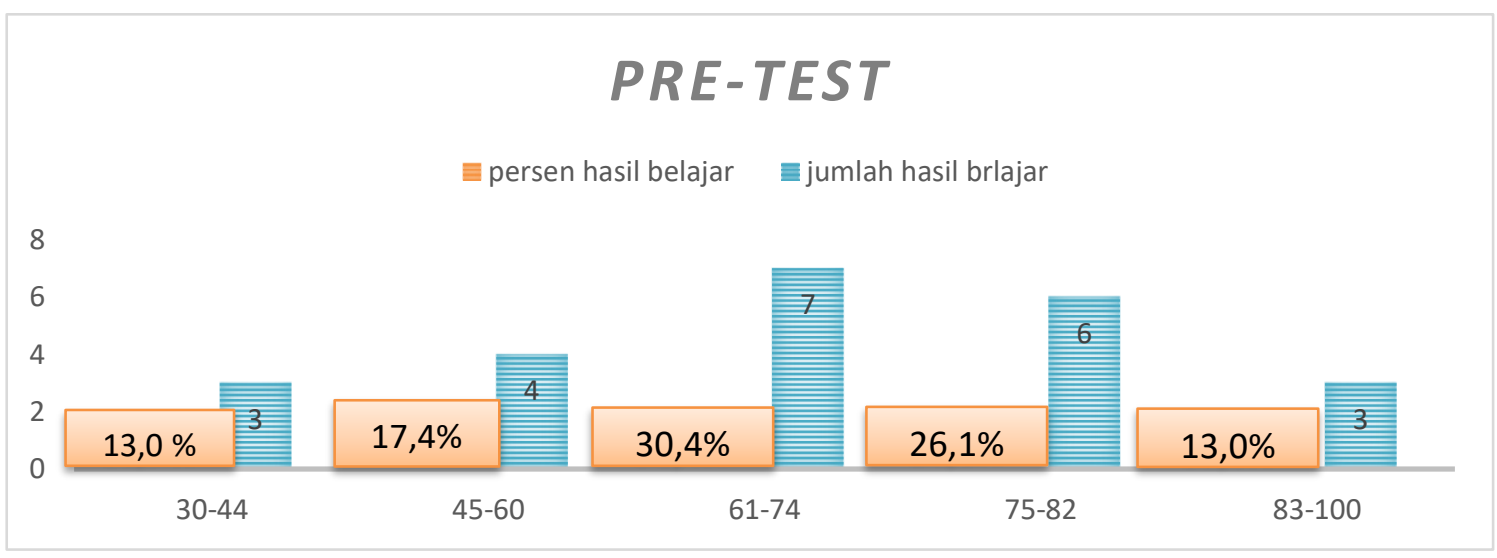

Gambar : distribusi frekuensi variable hasil belajar Pre-Test

Rentang data yang dihitung dengan rumus nalai maksimal-nilai minimal, sehingga diperoleh rentang data Pos-Test yaitu:

Tabel 2 Frekuensi Pos-Test

\begin{tabular}{|l|l|l|l|l|}
\hline No & Kelas Interval & $\begin{array}{l}\text { Frekuensi } \\
\text { absolut }\end{array}$ & $\begin{array}{l}\text { Frekuensi } \\
\text { relatif }\end{array}$ & Kategori nilai \\
\hline 1 & $30-44$ & 0 & $0 \%$ & Sangat rendah \\
\hline 2 & $45-60$ & 2 & $8,7 \%$ & Rendah \\
\hline 3 & $61-74$ & 9 & $39,1 \%$ & Sedang \\
\hline 4 & $75-82$ & 8 & $34,8 \%$ & Tinggi \\
\hline 5 & $83-100$ & 4 & $17,4 \%$ & Sangat tinggi \\
\hline & Jumlah & 23 & $100 \%$ & \\
\hline
\end{tabular}

Berdasarkan distribusi variable hasil belajara dapat dilihat dari diagram batang dibawah ini: 


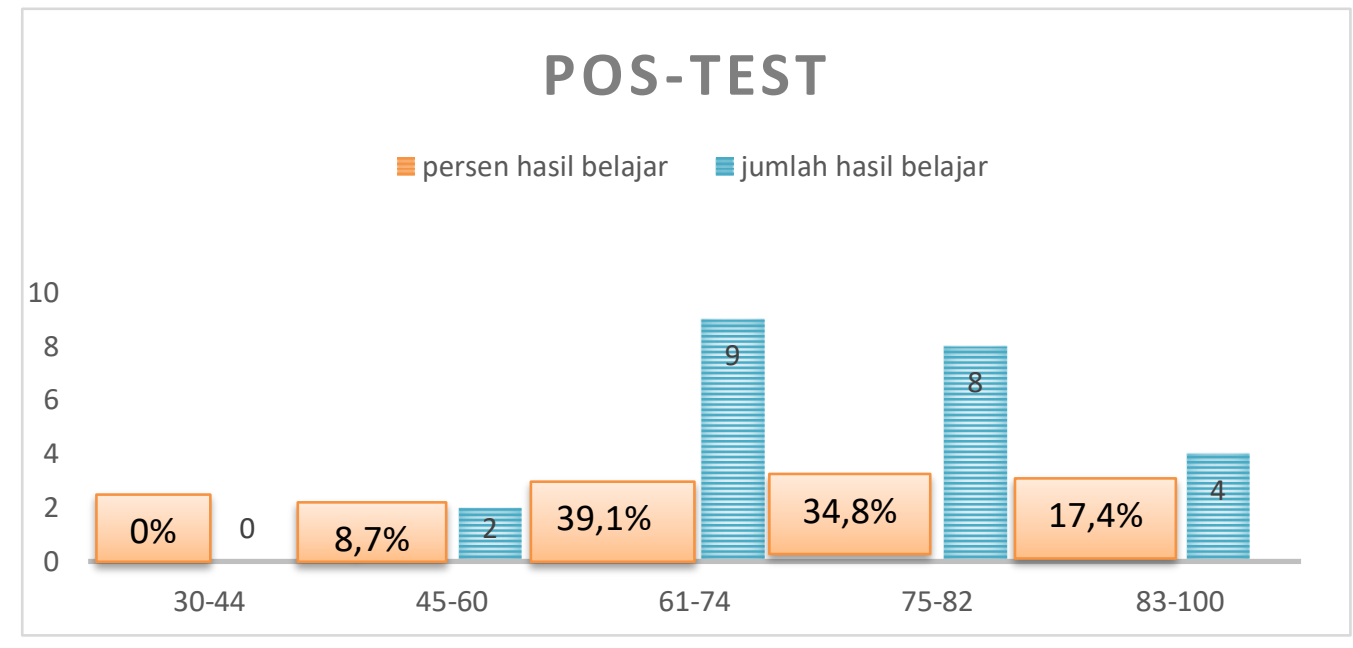

Gambar : distribusi frekuensi variable hasil belajar Pre-Test

\section{PENGUJI HIPOTESIS}

Uji hipotesis setelah dilakukan untuk melihat dan menentukan apakah terdapat pengaruh model Time Token yang signifikan dengan menggunakan uji Shapiro wilk dengan menggunakan aplikasi SPSS 20. Beriikut ini hasil dari analisis normalitas yaitu:

Tabel 3 Uji hipotesis

\begin{tabular}{|l|r|r|rr|}
\hline & \multicolumn{3}{|c|}{ Shapiro-Wilk } \\
\cline { 2 - 5 } & \multicolumn{1}{|c|}{ Statistic } & \multicolumn{1}{c|}{ df } & \multicolumn{2}{c|}{ Sig. } \\
\hline Pre-test Hasil belajar IPA & .953 & 23 & .339 \\
\hline Pos-test Hasil belajar IPA & .924 & 23 & .082 \\
\hline
\end{tabular}

Uji hipotesis yang digunakan dalam penelitian ini membandingkan hasil belajar siswa sebelum dan telah diberikan perlakuan yang telah dilakukan dengan kata lain uji ini digunakan untuk melihat ada tidaknya perubahan yang signifikan antara pre-test dan post-test. -tes. Kriteria pengujian yang digunakan adalah $\mathrm{p}$ value $<0,5$ maka Ho ditolak, sebaliknya jika $\mathrm{p}$ value $>0,5$ maka Ho diterima. 
Tabel 4 Paired Samples Test

\begin{tabular}{|c|c|c|c|c|c|c|c|c|}
\hline & \multicolumn{5}{|c|}{ Paired Differences } & \multirow[t]{3}{*}{$\mathrm{t}$} & \multirow[t]{3}{*}{$\mathrm{df}$} & \multirow{3}{*}{$\begin{array}{l}\text { Sig. } \\
(2- \\
\text { tailed) }\end{array}$} \\
\hline & \multirow[t]{2}{*}{ Mean } & \multirow[t]{2}{*}{ Std. Deviation } & \multirow[t]{2}{*}{ Std. Error Mean } & \multicolumn{2}{|c|}{$\begin{array}{c}95 \% \\
\text { Confidence } \\
\text { Interval of the } \\
\text { Difference }\end{array}$} & & & \\
\hline & & & & Lower & Upper & & & \\
\hline Pair 1 PRE - POST & -10.913 & 14.158 & 2.952 & -17.035 & -4.791 & -3.697 & 22 & .001 \\
\hline
\end{tabular}

Hasil uji-t sampel berpasangan dengan taraf signifikan 95\% $(\alpha=0,05)$. Berdasarkan tabel tersebut dapat dilihat bahwa sig. $(001$ tailed $)=0,000$ dalam hal ini berarti nilai p lebih kecil dari atau $(0,001<0,05)$. Sesuai dengan kriteria pengujian hipotesis, $\mathrm{p}$ value $<0,05$, maka $\mathrm{H} 0$ ditolak dan $\mathrm{H}$ diterima. Terdapat perbedaan skor siswa sebelum diberikan perlakuan atau pre-test dan skor setelah diberikan perlakuan atau post-test. Sehingga dapat dikatakan bahwa terdapat pengaruh yang signifikan penggunaan model pembelajaran kooperatif tipe Time Token terhadap hasil belajar IPA Tema 8 pada siswa kelas V SD di SDN 06 Sitiung.

\section{PEMBAHASAN}

Pembahasan yang terjadi adalah pembelajaran IPA di kelas v SDN 06 sitiung siswa kurang aktif dalam proses pembelajaran dan rendahnya hasil belajar siswa pada IPA. Hasil belajar siswa yang diberikan penerapan model Time Token memperoleh nilai rata-rata 77 , sedangkan sebelum diberikan perlakuan hasil pre-test diperoleh nilai ratarata 66. Hasil tersebut dapat dikatakan masih sangat rendah dimana rata-rata kelas belum mampu mencapai KKM, maka sebelum dilakukan pengujian persyaratan analisis yaitu menggunakan uji normalitas dan uji hipotesis. Setelah dilakukan dua kondisi pengujian, dapat diketahui bahwa data penelitian menunjukkan normal dan abnormal. Ada 9 siswa yang menyelesaikan pre-test dan meningkat di post-test menjadi 19 dari 23 siswa. Hasil ini diikuti dengan perolehan nilai post-test yang sangat baik, dimana skor tertinggi mencapai 98 dan skor terendah adalah 50.

Hasil analisis yang diperoleh pada uji paired sample t-test dengan taraf signifikansi 95\% $(\alpha=0,05)$ yaitu sig $(2$-tailed $)=001$. Sesuai dengan kriteria pengujian hipotesis, $\mathrm{p}$ value $<0,05$ dalam hal ini kasus $001<0,05$, maka H0 ditolak dan Ha 
diterima. Sehingga dapat dinyatakan bahwa terdapat pengaruh yang signifikan penerapan model kooperatif tipe Time Token terhadap hasil belajar IPA tema 8 Tetangga Sahabat Kita di kelas V SDN 06 Sitiung.

\section{DAFTAR PUSTAKA}

Amalina,S.(2014). Implementasi Metode Time Token Dalam Peningkatan Kemampuan Interaksi Sosial Anak di Tk Tarbiyatul Banin li Salatiga. Universitas Negeri Semarang.

Amelia Popla, I. A. (2019). Penerapan Model Pembelajaran Time Token Terhadap Peningkatkan Hasil Belajar Konsep Ciri-Ciri Makhluk Hidup Pada Siswa Kelas Viii Smp Kristen Ypkpm Ambon. Biopendix: Jurnal Biologi, Pendidikan Dan Terapan, 5(2), 82-88. hrtps ://doi .org/ 10 .30598/biopendixvol5issue2page82-88

Ariyanto, M. (2016). Peningkatan Hasil Belajar IPA Materi Kenampakan Rupa Bumi Menggunakan Model Scrambl, 3(2), 134-140.

Dewi, S. (2017). Pengaruh Kombinasi Pembelajaran NHT (Numbered Heads Together) dan STAD (Student Teams Achievement Division) Terhadap Hasil Belajar IPA Peserta Didik Kelas V

Indriani, F. (2015). Kompetensi Pedagogik Mahasiswa Dalam Mengelola Pembelajaran Tematik Integratif Kurikulum 2013. Pada. 2(2), 8794

Nurwati. (2017). Penerapan Model Pembelajaran Time Token Terhadap Pencapaian Hasil Belajar Fisika Kelas X. Jurnal Pendidikan Fisika, I, 237.

Prananda, G. (2019). Jurnal llmiah Pendidikan Dan Pembelajaran Rnal llmiah Pendidikan Dan Pembelajaran Fakultas Tarbiyah Universitas Muhammadiyah Aceh Akultas Tarbiyah Universitas Muhammadiyah Aceh Vol. Ilmiah Pendidikan Dan Pembelajaran, $6(2)$.

Prananda. G (2020). Pengembangan Media Pembelajaran Tema 6 Subtema 2 Untuk Siswa Kelas V SD Negeri 17 Pasar Masurai. Jurnal Dharma PGSD. 
Prananda, G., \& Hacliyanto. (2019). Korelasi antara Motivasi Belajar dengan Hasil Belajar Siswa dalam Pembelajaran IPA di Sekolah Dasar. Jurnal Basicedu, 3(3), 909-915.

Resnani. (2014). Penerapan Model Discovery Learning untuk Penlngkatan Aktivitas dan HasiL Belajar Siswa pada Pembelajaran Tematik Kelas VC SDIT Generasi Rabbani Kota Bengkulu. 12(1), 9-14.

Sugiyono. (2017). Metode Penelitian Kuantitatif.

Warsiti. (2003). Pembentukan Karakter Siswa Sekolab Dasar Melalui Pembelaja ran $l P A .384-38$ 